\title{
Getting by with a little help from my friends... and family: immigrants and carpooling
}

\author{
Evelyn Blumenberg • Michael Smart
}

Published online: 5 March 2010

(c) The Author(s) 2010. This article is published with open access at Springerlink.com

\begin{abstract}
While much of the scholarly literature on immigrants' travel focuses on transit use, the newest arrivals to the United States make over twelve times as many trips by carpool as by transit. Using the 2001 National Household Travel Survey and multinomial logit mode choice models, we examine the determinants of carpooling. In particular, we focus on the likelihood of carpooling among immigrants - carpooling both within and across households. After controlling for relevant determinants of carpooling, we find that immigrants are far more likely to form household carpools than native-born adults and also are more likely than the native-born to form external carpools (outside the household). Moreover, when faced with the options of carpooling and public transit, immigrants-even recent arrivals-appear to prefer carpools over transit more strongly than the native born.
\end{abstract}

Keywords Immigration - Carpooling - Mode choice modeling - Travel demographics

\section{Introduction}

More than 33 million immigrants live in the United States, comprising over $11 \%$ of the nation's population (U.S. Census Bureau 2004). In 2006, nearly 1.3 million additional foreign-born individuals became legal permanent residents of the United States (U.S. Department of Homeland Security 2007a), and the federal government estimates that approximately the same number of unauthorized immigrants entered the country in the same year (U.S. Department of Homeland Security 2007b). Immigration plays a large role in population growth, and the changing demographics of the nation have influenced the way that Americans collectively live, work, shop, and travel.

E. Blumenberg · M. Smart ( $\square)$

UCLA Institute of Transportation Studies, 3250 Public Policy Building,

Los Angeles, CA 90095-1656, USA

e-mail: mikesmart@gmail.com

E. Blumenberg

e-mail: eblumenb@ucla.edu 
Despite these important trends, transportation scholarship on immigration has lagged. In part, this deficit may be due to the limited travel data available on immigrants; for example, only the most recent iteration of the National Household Travel Survey (the 2001 NHTS, successor to the Nationwide Personal Transportation Survey) contains detailed information on immigrant status, year of entry, and country of origin. Research has tended to focus on immigrants' relatively high rates of public transportation usage and low automobile ownership rates, and has tended to rely on descriptive statistics (Casas et al. 2004; Myers 1996; Purvis 2003).

While much of the scholarship on immigrants' travel behavior has focused on the use of public transportation, this mode serves only a small fraction (2.8\%) of immigrants' trips. Indeed, data from the National Household Travel Survey (NHTS) show that even the newest immigrants to the United States-those in the country 5 years or less-make over twelve times as many daily trips by carpool (defined here as all trips by multiple-occupant vehicle) as by public transit (U.S. Department of Transportation 2004). Our paper analyzes the determinants of carpooling using data from the 2001 NHTS. We employ a nested logit model (NLM) to examine the effects of immigrant status and tenure in the United States on the likelihood of two types of carpooling - household-internal carpools and external carpools, which we define as carpools that include members from outside the respondent's household. Analysis of immigrants' reliance on these two types of carpooling provides a better understanding of the determinants of carpooling. Moreover, it suggests additional determinants of carpooling that might better explain the prevalence of this travel mode among immigrants and, perhaps, facilitate its use. We return to this last point in our analysis of the findings.

\section{What explains carpooling?}

Much of the existing carpooling literature is motivated by an interest in transportation demand management. Scholars have sought to understand carpooling to devise better strategies to encourage more of it and, therefore, reduce overall vehicle miles traveled. The focus, in other words, is on carpooling as the means to relieving the negative externalities associated with driving such as traffic congestion and air pollution. Analyses of carpooling also can improve our understanding of household behavior, and particularly, why and how households share resources such as automobiles.

Existing scholarship on carpooling shows correlations-albeit not particularly strong ones-between carpooling and socio-demographic, trip, and attitudinal characteristics. In most studies, carpooling is positively related to lower incomes, more limited access to household vehicles, the number of workers in the household, and trip length (Brownstone and Golob 1992; Ferguson 1997; Hwang and Giuliano 1990; Teal 1987). Less well understood is the relationship between carpooling and attitudes; however, attitudinal factors such as environmental or pro-social concerns and trust in others tend to be positively associated with carpooling (Van Lange et al. 1998).

Despite the high rates of carpooling among immigrants, the relationship between immigrant status and carpooling has received little scholarly attention. Existing transportation studies of immigrants largely center on their use of public transit and their limited access to automobiles. Studies find that public transit use declines with years in the U.S. and, conversely, automobile ownership and use increases (Blumenberg and Shiki 2007; Chatman and Klein 2009; Casas et al. 2004; Chatman and Klein 2009; Heisz and Schellenberg 2004; McGuckin and Srinivasan 2003; Myers 1996; Pisarski 2006; Purvis 2003; Rosenbloom 1998; Tal and Handy 2005). 
Only a small number of studies include an analysis of immigrants and carpooling (Chatman and Klein 2009; Cline et al. 2009; Myers 1996; Pisarski 2006; Purvis 2003). These studies use various Census data but report similar findings - the decline of immigrant carpooling to work with years of residence in the U.S. Myers (1996) tells a slightly more nuanced story. He draws on U.S. Census data from the 1980 and 1990 Public Use Microdata Samples (PUMS) to examine changes in the carpooling behavior of recent immigrants by sex, race, and age cohorts over a 10-year period in Southern California. He finds that among male immigrants, older white and Asian adults carpool at higher rates than younger workers. In contrast, carpooling among female immigrants tends to decline with time in the U.S. Additionally, a few qualitative studies of the economic strategies of immigrants highlight the importance of carpooling. In particular, these studies emphasize the role of payment for rides (Bohon et al. 2008; Lovejoy and Handy 2008) and, in some cases, immigrants' use of automobiles as moneymaking ventures, in the form of informal taxi service (Mahler 1995).

Indeed, immigrants commute by carpools more frequently than do native-born adults. However, few of the immigrant studies address the determinants of carpooling and, in particular, the extent to which carpooling can be explained by standard characteristics such as household size, income, and trip distance. Nor do these studies examine the use of carpools for non-work travel where carpooling is most prevalent. Further, these studies of immigrants and carpooling do not differentiate between two very different types of carpools - those that form within households (household-internal carpools) and those than form across households (external carpools). The extent to which immigrants rely on these two carpooling types provides a better understanding of carpooling behavior and, perhaps, suggests additional determinants of carpooling that might better explain the prevalence of this mode of travel among this population group.

\section{Data and methodology}

For our analysis, we rely on the 2001 National Household Travel Survey (NHTS), a nationally representative travel-diary survey. We use this dataset first to describe the characteristics and travel patterns of immigrants and, second, to model the determinants of mode choice. Here we focus on immigrants' relative likelihood of carpooling both within and across households. We discuss the data and methodological approach below.

Our unit of analysis is the single-day trip of less than 75 miles made by respondents 18 years of age or older. We included data for all trip purposes in the dataset. After removing records that did not fit these criteria, or for which data were missing, we had a sample size of 151,507 trips made by 34,970 individuals in 21,269 households, for an average of 7.4 trips per household or 4.3 trips per person daily.

Immigrants comprise nearly $8.4 \%$ of our weighted sample, with 2,842 individuals in the following categories: 390 recent immigrants (0-4 years in the United States), 385 immigrants who had resided in the United States for 5-9 years, and 2,167 who had resided in the U.S. 10 years or longer. ${ }^{1}$ A weighting scheme, provided by the NHTS, corrects for differential trip frequency by household.

Table 1 summarizes the basic characteristics for native- and foreign-born adults in our sample by years in the U.S. For most variables, values progress monotonically from the

1 There are significant differences between the sample of immigrants in the NHTS and the 2000 U.S. Census; these differences are discussed in Appendix 1. 
Table 1 Characteristics by immigrant status, adult population, 2001 (weighted)

\begin{tabular}{|c|c|c|c|c|}
\hline & \multicolumn{3}{|c|}{ Immigrants } & \multirow[t]{2}{*}{ Native-born } \\
\hline & $0-4$ years & 5-9 years & $10+$ years & \\
\hline \multicolumn{5}{|l|}{ Personal characteristics } \\
\hline Female & $46 \%$ & $48 \%$ & $51 \%$ & $52 \%$ \\
\hline Non-White & $67 \%$ & $68 \%$ & $55 \%$ & $13 \%$ \\
\hline Median age & 32 & 35 & 46 & 48 \\
\hline No high school diploma & $15 \%$ & $17 \%$ & $17 \%$ & $8 \%$ \\
\hline At least some college & $65 \%$ & $55 \%$ & $57 \%$ & $57 \%$ \\
\hline \multicolumn{5}{|l|}{ Household characteristics } \\
\hline Ratio of vehicles to adults ( $16+$ years) & 0.76 & 0.89 & 1.05 & 1.19 \\
\hline Mean Household size & 3.4 & 3.7 & 3.4 & 2.9 \\
\hline Household income $<\$ 30,000$ & $42 \%$ & $33 \%$ & $26 \%$ & $23 \%$ \\
\hline Share of household in nuclear family & $77 \%$ & $82 \%$ & $88 \%$ & $91 \%$ \\
\hline \multicolumn{5}{|l|}{ Trip characteristics } \\
\hline Share of trips work-related & $31 \%$ & $35 \%$ & $30 \%$ & $28 \%$ \\
\hline Mean trip length (miles) & 9.2 & 9.7 & 9.6 & 9.8 \\
\hline Mean daily trips & 3.8 & 3.8 & 4.1 & 4.4 \\
\hline \multicolumn{5}{|l|}{ Geographic characteristics } \\
\hline Residential density $\left[1000 / \mathrm{mi}^{2}\right]$ & 9.0 & 9.3 & 7.5 & 3.5 \\
\hline Employment density $\left[1000 / \mathrm{mi}^{2}\right]$ & 4.2 & 5.1 & 3.8 & 1.5 \\
\hline Living in urban area $3+$ million population & $54 \%$ & $59 \%$ & $58 \%$ & $28 \%$ \\
\hline$N$ (individuals) & 390 & 385 & 2,167 & 32,028 \\
\hline
\end{tabular}

Source: 2001 National Household Travel Survey

newest immigrants through the less-recent immigrant categories to native-born levels, evidencing processes of assimilation (becoming like native-born adults) and possible differential attrition. (For example, certain immigrant groups may only stay in the United States for short time periods.)

While Table 1 provides detailed descriptive statistics on immigrant groups, a few points are worth discussing in detail. Immigrants tend to live in larger households than do the native-born (2.9 household members); recent immigrants and immigrants in the country 10 years or more have households with, on average, 3.4 members. Additionally, household structure differs considerably. Among native-born households, an average of $91 \%$ of household members are members of the same nuclear family; in contrast, for the newest immigrants, this figure is $77 \%$. As noted in other studies, immigrants in our sample have a stronger bi-modal educational distribution than is the case for native-born adults, with $15 \%$ of the newest immigrants arriving without a high school diploma (compared to just $8 \%$ of the native-born) and $65 \%$ having at least some college, compared to just $57 \%$ of the nativeborn. The share of immigrants with college degrees decreases by tenure cohort, with only $57 \%$ of the most senior cohort having college degrees. This likely is due to generational effects and potential differential attrition of high-skilled corporate 'sojourner' immigrants.

As noted in other studies (Tal and Handy 2005), we observe higher household incomes over time among immigrant cohorts, and these higher incomes typically are expected to result in more frequent use of automobile modes, and single occupancy vehicle (SOV) travel in particular. As one might expect from immigrants' overall lower incomes, 
immigrants also tend to own fewer cars per household member than do the native-born. Among immigrants who have been in the U.S. fewer than 10 years, the ratio of vehicles to adults is less than one; in other words, many immigrant drivers must compete with household members for the use of the vehicle.

Immigrants tend to live in neighborhoods with higher residential densities, with mean residential densities approximately two and one half times as high as the neighborhoods in which native-born households live (3,500 persons per square mile). Immigrant neighborhoods for all three tenure groups also tend to have higher employment densities than is the case for neighborhoods in which native-born Americans live. Finally, immigrants are more than twice as likely as the native born (58\% vs. 28\%) to live in large metropolitan areas with more than three million inhabitants. We expect many of these demographic differences to influence carpooling rates among immigrants, though likely not explain the phenomenon entirely.

The data suggest that, in general, immigrants progress toward the incomes and residential and travel patterns of native-born adults. However, the cross-sectional nature of the data may mask cohort effects, or variation in behavior that arises from factors (historical, cultural, economic, etc.) affecting or otherwise associated with particular immigrant waves. Indeed, the demographic characteristics of immigrants to the United States have shifted over time, reflecting changes in the global economy, immigration policies that influence the relative permeability of U.S. borders, and the location of major political upheavals and wars. Once predominantly white and European, the U.S. foreign-born population is now increasingly Hispanic and Asian. Among recent immigrant respondents in our sample (those who have lived in the U.S. for less than 5 years), only $31 \%$ are white; $40 \%$ are Hispanic and $20 \%$ are Asian.

\section{Model specification}

We first used a multinomial logistic model to examine the effect of a series of independent variables, including immigrant status, on mode choice. The multinomial logistic model assumes that the likelihood of selecting one choice over another remains unchanged regardless of the availability of other choice options. This property, known as the irrelevance of independent alternatives (IIA), is violated in the case where choices act as substitutes for one another (such is the case in the famous Red Bus/Blue Bus case introduced in McFadden 1974). Our initial model indeed violated the IIA property. To overcome this problem, we developed a nested logistic model, clustering non-single-occupancy travel modes in one branch. As depicted in Fig. 1, to estimate the determinants of mode choice, the first-level branching differentiates between single-occupancy vehicles (SOV) and all other modes. The second-level non-SOV branch includes household-internal carpool, external carpool, public transit, and non-motorized modes (biking and walking).

For this analysis, we focus on the determinants of two types of carpooling: householdbased carpooling and external (non-household-exclusive) carpooling. We define household carpools as trips made by respondents who either are the drivers or passengers in cars with other passengers, all of who are from the respondents' household. ${ }^{2}$ External carpools are

\footnotetext{
2 Some passengers are children. The NHTS includes a question on whether respondents are making trips for themselves or chauffeuring. Chauffeuring includes transporting someone, dropping off and waiting, or dropping someone off. Although not all, many of these trips likely involve children. The difference in household-chauffeuring rates between immigrants and native-born adults is statistically significant, though
} 
Fig. 1 Nesting structure

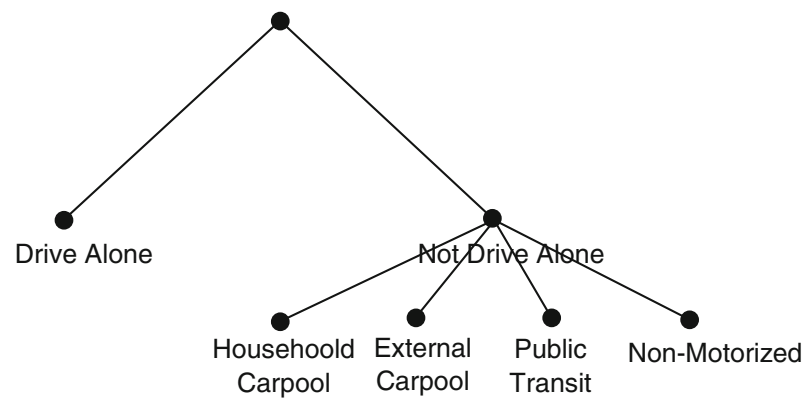

those in which respondents are either the driver or a passenger in cars with other passengers, at least one of whom comes from outside of the respondents' household. Thus, an automobile trip with one's cohabitating spouse is considered a "household carpool," whereas the same configuration plus a neighbor would be considered an "external carpool." Seventy percent of all carpools in our sample are household carpools, a figure comparable to that found by Ferguson (1997) in his analysis using the 1990 Nationwide Personal Transportation Survey.

Ideally, we would use longitudinal data on the behavior of specific individuals and their households over time. Unfortunately, these data are not available; therefore, we approximate changes over time by relying on cross-sectional data and including a variable describing the number of years immigrant respondents have lived in the United States, as well as its squared term. Though we admit the cross-sectional nature of our analysis is imperfect, we attempt to account for confounding changes in immigrant cohorts by controlling for relevant factors such as age, race, ethnicity, and level of education. We know from previous studies that the travel mode of immigrants varies also by race and ethnicity (Blumenberg and Shiki 2007; Myers 1996; Tal and Handy 2005). Consequently, in a separate set of models, we examine the interaction between the two.

In addition to nativity and years in the U.S., our models include a number of other factors associated with mode choice and, more specifically, with the likelihood of carpooling. These variables fall into four categories, personal, household, trip, and geographic characteristics, and are included in Table 2. They also correspond to the descriptive statistics shown in Table 1. Previous studies on carpooling are few and the findings inconsistent. In general, however, the studies show that carpoolers make longer trips than solo drivers, have lower incomes and less education, and live in households where there are fewer vehicles per worker (Charles and Kline 2006; Ferguson 1997; Teal 1987). ${ }^{3}$ We control for all four of these factors with the variables - trip miles, educational attainment (no high school, high school diploma, and some college), the log of household income, and the ratio of household vehicles to adults.

Household structure also influences carpooling rates; those who are married (Charles and Kline 2006; Teal 1987), women with small children (Ferguson 1997), and workers in households with older children (Ferguson 1997) are more likely to form carpools. Further,

Footnote 2 continued

the rates for both groups are relatively small $-4.6 \%$ of all trips for immigrants and $3.7 \%$ of all trips for native-born respondents. We tested the robustness of our model by eliminating all chauffeuring trips; the coefficients changed only slightly, and our overall findings remained the same.

${ }^{3}$ Ferguson (1997) finds that those living at or near the poverty line are more likely to carpool; however, among workers who live above the poverty line, family income is not significant. 
Table 2 Determinants of carpool (relative to SOV)

\begin{tabular}{|c|c|c|}
\hline Characteristics & Definition & $\begin{array}{l}\text { Predicted direction } \\
\text { of relationship }\end{array}$ \\
\hline \multicolumn{3}{|l|}{ Individual characteristics } \\
\hline Nativity status & Nativity status; immigrant status by years in the U.S & + \\
\hline Sex & Male, female & $?$ \\
\hline Race/ethnicity & $\begin{array}{l}\text { Non-Hispanic white, black, Hispanic, Asian, } \\
\text { multiple/other }\end{array}$ & $?$ \\
\hline Age & Age of respondent & - for working age \\
\hline Educational attainment & $\begin{array}{l}\text { No H.S. diploma., H.S. diploma but no college; at } \\
\text { least some college }\end{array}$ & - \\
\hline \multicolumn{3}{|c|}{ Household characteristics } \\
\hline Auto access & $\begin{array}{l}\text { Ratio of household vehicles to adults (16+ years) in } \\
\text { household }\end{array}$ & - \\
\hline Household size & Number of individuals in household & $?$ \\
\hline Household income & Mid-point of reported ranges $(\log )$ & - \\
\hline Nuclear family & $\begin{array}{l}\text { Share of household that is part of respondents } \\
\text { nuclear family }\end{array}$ & + \\
\hline \multicolumn{3}{|l|}{ Trip characteristics } \\
\hline Length & Trip miles & + \\
\hline \multirow[t]{4}{*}{ Trip purpose } & Work (to/from work, work-related) & $?$ \\
\hline & Shop (shopping) & $+(\mathrm{HH}$ carpool $)$ \\
\hline & $\begin{array}{l}\text { Personal (family/personal, school or church, } \\
\text { doctor/dentist) }\end{array}$ & \\
\hline & Social (visit friend, social, recreational) & $+(\mathrm{HH}$ carpool $)$ \\
\hline \multicolumn{3}{|c|}{ Geographic characteristics } \\
\hline MSA size & $\begin{array}{l}<250,000 ; 250,000-500,000 ; 500,000-1 \text { million; } \\
\quad 1-3 \text { million; } 3+\text { million }\end{array}$ & - \\
\hline New York City & Resident of New York City & - \\
\hline$\%$ Renters & Percentage of renters in census tract & \\
\hline Residential density & Population density by census tract ( $\log )$ & - \\
\hline Employment access & Employment density by census tract $(\log )$ & + \\
\hline
\end{tabular}

most carpools consist of family members (Ferguson 1997); therefore, we might expect a positive relationship between carpooling and the share of household members that belong to a respondent's nuclear family.

We also control for sex as well as household size. Findings with respect to race and ethnicity are inconclusive largely because many of the studies omit racial and ethnic controls. Ferguson (1997), however, finds that Hispanics are more likely to use household carpools, and that African Americans are more likely to carpool with non-household members. In our model, we control for race and ethnicity (Non-Hispanic white, black, Hispanic, Asian, multiple/other).

Finally, the studies suggest that carpooling is associated with the size and urban structure of metropolitan areas. For example, carpooling is negatively related to residential density and metropolitan area size (Charles and Kline 2006; Ferguson 1997; Teal 1987) since in many dense and large urban areas public transit serves as a reasonable substitute to travel by automobile. We use four population size categories to control for the size of the 
metropolitan area and include a measure of residential density by census tract. Moreover, we include a measure of employment density (jobs per square mile by census tract) that measures respondents' access to employment (and thus, likely to activity sites), hypothesizing that greater access to employment is related to the use of alternative modes of travel, particularly for the commute. Separately, we identify respondents who live in New York City, the location of $28 \%$ of all transit commute trips in the U.S. (U.S. Census Bureau 2000).

\section{Immigrants and travel mode}

As previously mentioned, the 2001 NHTS shows that, indeed, immigrants travel by carpool more than native-born Americans, and that newer immigrants tend to carpool more than less-recent arrivals. Table 3 shows the modal split among adult respondents by immigrant status and tenure in the United States. Immigrants in this sample make use of "alternative" modes of transportation far more regularly than do native-born Americans. Almost twothirds $(63 \%)$ of trips made by the newest immigrants to the United States were by modes other than single-occupancy vehicle, while native-born Americans make less than half their trips by these modes $(46 \%)$. Immigrants are more likely to travel by carpool than nativeborn travelers, with $39 \%$ of trips made by the newest immigrants taking place in household-based carpools; for native-born Americans, the figure is 30\%. External carpooling is also somewhat more frequent among new immigrants, with $14.6 \%$ of new immigrants using this mode, compared with $13 \%$ of native-born adults. Among recent immigrants, the percentage of carpooling trips (54\%) substantially exceeds the percentage taken by single occupancy vehicle $(37 \%)$.

Recent immigrants also rely on other alternative modes of travel in higher percentages than native-born adults. For example, among recent immigrants, over $9 \%$ of trips occur on foot, bicycle, and public transit compared to $3.5 \%$ among native-born adults. Immigrants continue to use these modes more than native-born adults even after ten or more years in the U.S.

Similar to findings from previous studies, we find that the percentage of trips taken by single occupancy vehicle (SOV) increases with time in the U.S. Thirty-seven percent of recent immigrants travel by SOV, a figure that rises to $48 \%$ among immigrants living in the

Table 3 Weighted distribution of mode by respondent's immigrant status and tenure in United States, all trips, 2001

\begin{tabular}{lllll}
\hline & \multicolumn{2}{l}{ Immigrants } & & \multirow{2}{*}{ Native-born } \\
\cline { 2 - 5 } & 0-4 years & 5-9 years & 10+ years & \\
\hline Single occupancy vehicle & $37.3 \%$ & $43.9 \%$ & $47.9 \%$ & $53.7 \%$ \\
Household carpool & 39.2 & 33.7 & 33.7 & 29.9 \\
External carpool & 14.6 & 14.3 & 12.7 & 13.0 \\
Public transit & 4.4 & 5.1 & 2.3 & 1.0 \\
Walk/bike & 4.6 & 3.0 & 3.5 & 2.5 \\
Total & $100.1 \%$ & $100.0 \%$ & $100.1 \%$ & $100.1 \%$ \\
$N$ (records) & 1,466 & 1,454 & 8,861 & 139,726 \\
\hline
\end{tabular}

Source: 2001 National Household Travel Survey 
country 10 years or longer. Conversely, carpooling rates-both household-internal and external-as well as biking and walking decline with years in the United States. Certainly, some of the progression toward SOV usage can be attributed to the economic and geographic assimilation of immigrants observed in Table 1 . However, immigrant status, even controlling for these assimilation processes, may help to explain the continued prevalence of alternative modes of transportation.

\section{Predicting the determinants of carpooling}

We use statistical models to predict commute mode choice and, in particular, to understand better the independent effects of nativity, race/ethnicity, and years in the U.S. on carpooling rates. ${ }^{4}$ The detailed results of our first regression model are shown in Table 4 . The table reports logit coefficients and standard errors. At the first level of our model, we predict the likelihood of traveling by modes other than single occupancy vehicle (not SOV) as a function of automobile availability, the ratio of vehicles to the number of household members who are of driving age. Automobile availability may be thought of as the extent to which household members must compete for the use of household vehicles. If there are a greater number of household adults than cars, it is more likely that some household members will use alternative modes of travel, including carpools. Increased automobile availability exhibits a strong negative association with non-SOV modes $(-0.226)$.

The other independent variables are located in the second level of the model. Many of these variables are statistically significant at the 0.05 level, and most carry the expected signs, and are thus consistent with previous travel behavior research. For example, our model suggests that household carpooling is positively related to household size $(0.334)$ and trip distance $(0.015)$, while negatively related to household income $(-0.024)$.

Trip purpose is also a strong determinant of carpooling, with work trips occurring far less frequently by both household-based carpools (logit coefficient -1.839 ) and external carpools (logit coefficient -1.726 ) when compared with personal trips. Of course, carpools can only occur when multiple occupants share common (or nearby) trip origins and destinations; these common pairings are far more prevalent for social, shopping, and familyserving trips than is the case for work-related travel (Richardson and Young 1981).

Similarly, sex plays an important role in the formation of carpools, with women far more likely to use carpools than men (logit coefficients of 0.339 for household carpools and 0.346 for external carpools), even when controlling for other factors. A human capital perspective would support the notion that men (who often have higher wages than women) would have primary access to a household vehicle, and thus would be more likely to travel alone for work-related and unrelated but chained trips. Other research has shown that women are more likely than men to prefer traveling as passengers, while men tend to prefer driving, and that women may experience higher levels of commute-related stress than men (Levin 1982; Novaco and Collier 1994).

Figure 2 summarizes the estimated effects, controlling for other variables, of immigrant status and tenure in the United States on each of the two carpool modes modeled. ${ }^{5}$ The figure reports the antilog of logit coefficients, or the "relative risk ratios" (RRRs). These

\footnotetext{
4 While the immigrant population in the United States exhibits strong demographic, economic, and locational traits, multiple collinearity tests confirm that our model does not suffer from this problem.

5 While not the principal focus of this research, the strong association between immigrant status and the use of transit and, particularly, non-motorized travel (bike, walk) is striking, and warrants further research.
} 


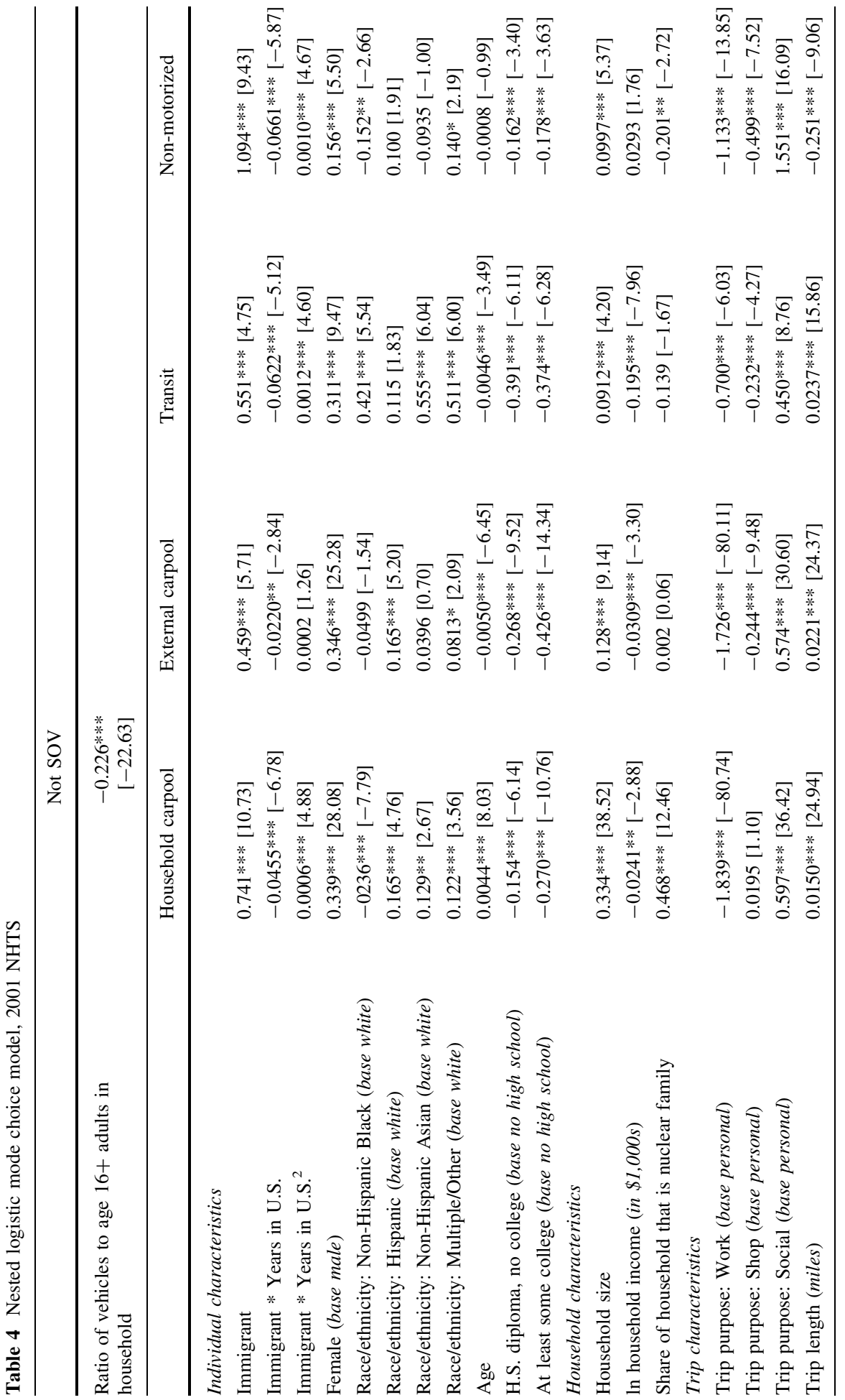




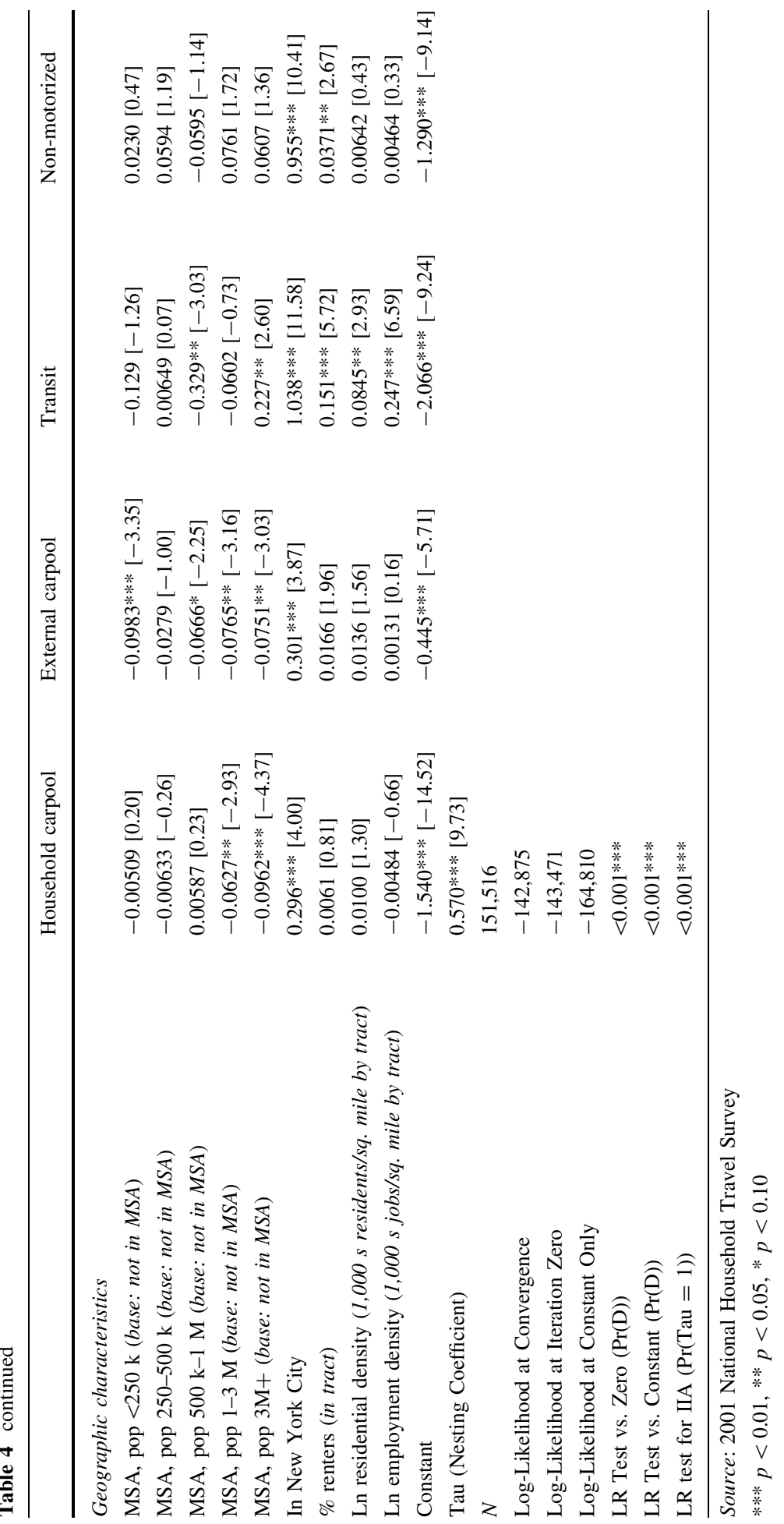


Fig. 2 Relative risk ratio for modes, single-occupant vehicle base and non-immigrant omitted category, immigrants by years in the U.S.

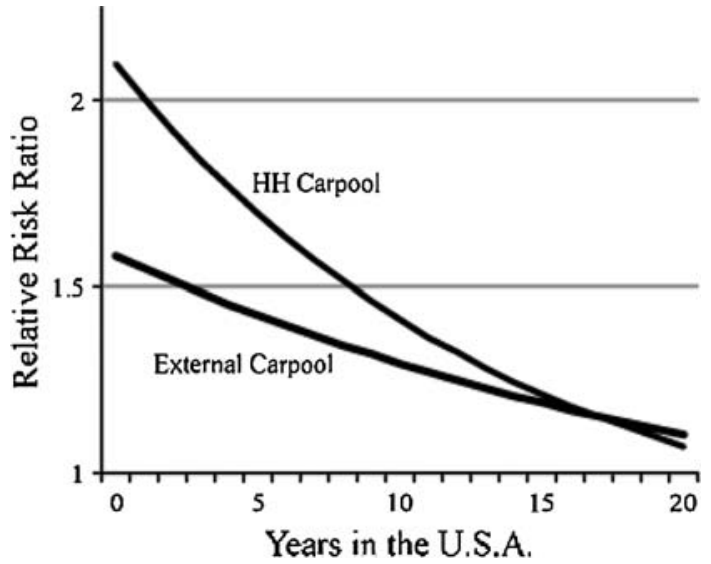

RRR statistics report the odds of immigrants choosing each carpool mode rather than the single-occupant vehicle (SOV) divided by the odds of the control group (non-immigrants) using that mode rather than SOV. Thus, relative risk ratios above 1.0 indicate an increased propensity to use that mode, compared with native-born Americans. We find that, even when controlling for household size, income, and other variables included in the model, household carpooling is far more common among immigrants than is the case for nativeborn Americans. We further find that this higher propensity to form household-based carpools decays steadily, suggesting that the effect of immigrant status on the formation of household carpools lessens over time, though these data are cross-sectional and the "decay" may simply be the result of unmeasured differences between new immigrants and older immigrants. Again, however, the extensiveness of our model likely accounts for much of the demographic change in immigrant cohorts.

We also find that, even controlling for all other variables in the model, immigrants are more likely to form external (including at least one non-household member) carpools than are the U.S.-born. The coefficients associated with immigrant status and external carpooling are smaller than those associated with household carpooling, and the difference is statistically significant. This finding indicates that, net of other variables, immigrant status is more strongly associated with the use of household carpools than external carpools. Interestingly, our model suggests a positive relationship between immigrant status and the use of public transportation as well. This finding contradicts an earlier study conducted using the NHTS, which finds that immigrants' higher propensity to use transit can be explained by standard socioeconomic and environmental variables (Tal and Handy 2005). These dissimilar findings using the same data likely are due to differences in modeling approaches. ${ }^{6}$ However, the finding is consistent with an earlier study using Census data that finds a positive independent effect of immigrant status on the use of public transportation for commute travel (Blumenberg and Shiki 2007).

Figure 3 shows the relative risk ratios for immigrant status for both types of carpooling, with transit as the reference mode. We include this figure to illustrate the strong association between the length of time an immigrant has been in the United States and the likelihood of choosing carpools over transit, even controlling for other relevant factors. This finding

\footnotetext{
${ }^{6}$ Tal and Handy (2005) do not use a nested model; they use logistic regression to predict the likelihood of travel by public transportation and non-motorized modes relative to travel by private vehicle.
} 
Fig. 3 Relative risk ratio for carpooling modes, transit base and non-immigrant omitted category, immigrants by years in the U.S. (non-significant coefficients set to zero)

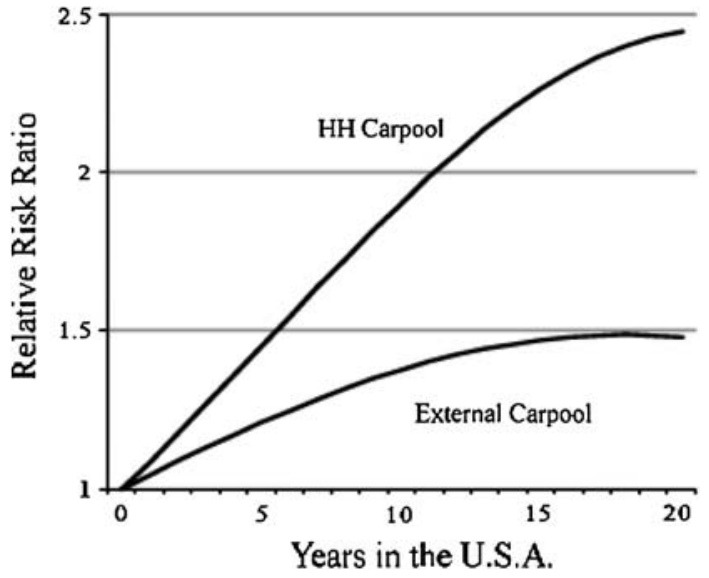

suggests that, while productive, the tendency of research to focus on immigrants' use of public transit may, in fact, serve to effectively overstate the phenomenon. When faced with the two major alternatives to driving alone, immigrants (even after controlling for other variables) are far more likely to choose carpools of both types than are native-born Americans, and this relative preference for carpooling over transit increases over time

We additionally tested the interaction between immigrant status and race/ethnicity. Immigrant ethnic subgroups may travel differently, owing to differences in preferences, ethnic settlement and employment patterns, and cultural norms. While the racial/ethnic groups provided by the NHTS are broad, and certainly mask significant within-subgroup heterogeneity such as that by country of origin, an investigation of average effects by these groups is worth undertaking. Table 5 shows these results; coefficients and standard errors are provided only for those variables that relate to immigrant status. Antilog coefficients

Table 5 Selected coefficients, logistic regression mode choice model with race/ethnicity interactions, 2001 NHTS

\begin{tabular}{|c|c|c|c|c|}
\hline & \multicolumn{2}{|c|}{ Household carpool } & \multicolumn{2}{|c|}{ External carpool } \\
\hline & Coef. & SE & Coef. & SE \\
\hline Immigrant $(N=12,012)$ & $0.663 * * *$ & 0.081 & $0.199 *$ & 0.092 \\
\hline Immigrant $*$ Black $(N=601)$ & -0.081 & 0.128 & -0.147 & 0.160 \\
\hline Immigrant $*$ Asian $(N=2,003)$ & $0.228 * *$ & 0.116 & -0.129 & 0.159 \\
\hline Immigrant $*$ Hispanic $(N=3,769)$ & $0.159 * *$ & 0.069 & $0.332 * * *$ & 0.092 \\
\hline Immigrant $*$ Multiple/Other $(N=455)$ & $0.669 * * *$ & 0.128 & $-0.424^{*}$ & 0.231 \\
\hline Immigrant $*$ Years in the U.S. & $-0.045 * * *$ & 0.008 & -0.004 & 0.010 \\
\hline Immigrant $^{*}$ Years in the U.S. ${ }^{2}$ & $0.001 * * *$ & $<0.001$ & $<-0.001$ & $<0.001$ \\
\hline$N$ (full model) & 151,507 & & & \\
\hline Log-Likelihood at Convergence & $-138,481$ & & & \\
\hline LR Test vs. Model 1 (Pr(D)) & $<0.001 * * *$ & & & \\
\hline
\end{tabular}

Source: 2001 National Household Travel Survey

Note: Full regression results available from authors; control variable antilog coefficients vary by less than $10 \%$ from those in the original model (Table 4)

$* * * p<0.01, * * p<0.05, * p<0.10$ 
(relative risk ratios) for all other coefficients differed from those in the first model by less than $10 \%$.

The by-ethnicity model exposes significant across-subgroup heterogeneity in carpool effects. The model suggests that, controlling for other variables, "multiracial/other" immigrants carpool more than all other immigrants, with Asian and Hispanic immigrants using household-based carpools slightly less, yet still more than White and Black immigrants, all of whom use household carpools far more frequently than the native born (again, controlling for other variables in the model). Similarly, Hispanic immigrants are far more likely than other immigrants to use external carpools, and nearly all immigrants exhibit a weakly significant increased propensity to use external carpools, controlling for other variables in the model. "Multiracial/other" immigrants exhibit a lower propensity to use external carpools than the native-born, though the coefficient is only weakly significant.

\section{Immigrants and resource sharing}

Our findings suggest that immigrant status is strongly associated with carpool formationabove and beyond characteristics typically associated with carpool usage, such as low incomes and large family sizes. While our findings do not indicate specific reasons for the higher incidence of carpooling among immigrants, the literature on post-immigration social capital building and integration suggests several possible hypotheses, and our findings support some hypotheses more strongly than others.

For instance, research suggests that immigrants make greater use of familial networks to compensate for lower levels of resources elsewhere, and this may well be the case for immigrants' travel behavior, as well. Strong family and kinship bonds among immigrants-particularly during their first years in the U.S.-may account for increased propensities to form household-based carpools. Indeed, research suggests that kinship networks motivate migration, and that many immigrants rely upon these networks to compensate for the limited availability of other forms of human and social capital (Boyd 1989; Choldin 1973). Research on immigration and transportation has shown that recent immigrants rely on help from family members to address their transportation needs. In a study of immigrants to Chicago, Choldin (1973) finds that $18 \%$ of immigrants received transportation assistance when they arrived: $69 \%$ of these from family members (either immediate family or other relatives) and $25 \%$ from friends, co-workers, or members of their neighborhood. We thus might hypothesize that one way in which immigrants rely upon family and kinship networks for transportation is through carpooling.

Theories related to ethnic resources would suggest that immigrants co-locate in order to maximize returns on culturally-defined social capital (Portes and Bach 1985). This theory might be extended to include the sharing of transportation resources. Immigrants use ethnically-, religiously- or culturally-defined stocks of social capital to maximize the utility of their limited resources. Spatial proximity to other immigrants of the same ethnic, religious, or cultural group facilitates the use of this social capital and helps to build social networks. The theory further suggests that, as some immigrants' financial situation improves, so too might their social networks expand and diversify, and the relative usefulness of life in an ethnic enclave declines (Esser 2004).

Immigrant neighborhoods traditionally have been located in the central city-ports of entry for recent immigrants. With time in the U.S., immigrants tend to assimilate spatially, moving to higher-income suburban neighborhood (Massey 1985). Among recent immigrants (those who have lived in the U.S. less than 10 years), over half live in central-city 
neighborhoods, compared to only $36 \%$ among immigrants who have lived in the U.S. more than 20 years (U.S. Census Bureau 2004). Many immigrants integrate into largely white suburban neighborhoods; however, in recent decades suburban ethnic enclaves have emerged (Alba et al. 1997; Li 1998; Logan et al. 2002).

Therefore, we might hypothesize that, just as new immigrants seek to maximize their utility by co-locating to share social networks, they may also be more likely to share transportation resources and utilize carpools. Focusing specifically on race, Charles and Kline (2006) find that individuals are more likely to engage in carpooling when their neighbors are similar to themselves, hypothesizing that carpooling represents a complex form of social capital production. With respect to immigrants, their residential location in ethnic enclaves also may provide a beneficial environment for the creation of racially-, culturally- and linguistically-based social capital necessary for the formation of carpools.

One might also theorize that the higher propensity of immigrants to use carpools may be the result of culturally-specific preferences or obstacles. For example, the lower licensing rates of women in some groups may account for a greater reliance on group travel, particularly with family members. Further, there is some evidence that immigrants may be somewhat more likely than native-born Americans to find employment in locations that employ many co-ethnics, thus increasing the chances of finding carpool partners with similar origins and destinations (Ellis et al. 2004). Other factors not modeled here also may account for the higher incidence of group travel, and this may prove to be a fruitful line of further inquiry.

Unfortunately, these potential explanatory factors cannot be tested using the 2001 NHTS. The dataset lacks detailed neighborhood characteristics, information on family and kinship networks, and the sample sizes necessary to analyze specific immigrant ethnic groups. However, these factors are worth noting as the basis for future research and as the theoretical underpinnings for understanding why immigrant carpooling rates cannot be explained entirely by standard variables such as income or trip distance.

\section{Conclusion}

The findings support our initial hypothesis that carpooling is associated with immigrant status, and that this association weakens over time. We find a stronger effect for householdbased carpools than for external carpools. We suspect that this increased propensity to share transportation resources within households may be the result of the higher relative value of stocks of familial social capital, relative to external (non-familial) stocks of social capital. We surmise that, during immigrants' first years in the United States, it may be simpler to share transportation resources with the household than with new and (often) unfamiliar neighbors, though this across-household sharing is still a more feasible and attractive option for many immigrant groups (we find an especially strong effect for Hispanic immigrants) than for the native-born.

Our findings also suggest that the tendency of researchers to focus on immigrants' use of public transportation as a significant part of the integration process may essentially overstates the use of this mode. While immigrants are far more likely than native-born Americans to use transit, they, like native-born Americans, are still more likely to travel by carpool than by public transportation-roughly twelve times as likely. Moreover, as Fig. 3 shows, our model suggests that the odds of immigrants choosing carpooling over transit increase considerably over time, controlling for other factors. 
When choosing between transportation alternatives (carpool and transit), all else equal, immigrants are much more likely to use household carpools than are native-born adults. Public transportation can work well in dense areas where origins and destinations are proximate and, consequently, travel times relatively short. However, many trips are better suited to travel by car-particularly those trips to or from neighborhoods in which transit service is limited. While immigrants tend to settle in denser, more transit-friendly environments than do native-born Americans, the urban form in which most Americans conduct their lives still strongly favors the automobile.

Finally, our findings suggest something important about the integration process of immigrants in the United States. As many new immigrants enter the country with relatively low stocks of social and, often, human capital, they may experience significant obstacles to achieving desired outcomes. In the face of these obstacles, our research suggests that many immigrants may exploit existing strong family and social ties to increase the expected likelihood of achieving desired outcomes such as employment, higher incomes, participation in meaningful social activities, and educational advancement.

\section{Appendix 1: Immigrant distribution: a comparison of data from the National Household Travel Survey (NHTS) and the U.S. Census}

When we compared the distribution of respondents by race and immigrant status in the NHTS to the estimated racial/ethnic distribution by immigrant status estimated in the 2000 Census, we find several discrepancies. First, immigrants comprise a smaller percentage of the NHTS sample than the Census. The 2000 Census estimated that immigrants comprised $14.5 \%$ of the population 18 years and older, while immigrants comprised only $8.4 \%$ of the NHTS sample. It is likely that the random-digit dialing method of data collection used in the NHTS significantly undercounts immigrants. Immigrants are more likely to have interrupted telephone service than native-born adults (McGuckin et al. 2001) and those with limited English language skills or undocumented legal status are, on average, less

Table 6 Comparison of racial/ethnic makeup of immigrants, 2001 NHTS and 2000 Public Use Microdata Sample

\begin{tabular}{|c|c|c|c|c|c|c|c|}
\hline & $\begin{array}{l}\text { White } \\
(\%)\end{array}$ & $\begin{array}{l}\text { Black } \\
(\%)\end{array}$ & $\begin{array}{l}\text { Hispanic } \\
(\%)\end{array}$ & $\begin{array}{l}\text { Asian } \\
(\%)\end{array}$ & $\begin{array}{l}\text { Multiple/other } \\
(\%)\end{array}$ & $\begin{array}{l}\text { Total } \\
(\%)\end{array}$ & $N$ \\
\hline \multicolumn{8}{|c|}{ National Household Travel Survey (2001) } \\
\hline $\begin{array}{l}\text { Immigrant, } \\
0-4 \text { years }\end{array}$ & 31 & 5 & 40 & 20 & 4 & 100 & 390 \\
\hline $\begin{array}{l}\text { Immigrant, } \\
\text { 5-9 years }\end{array}$ & 32 & 7 & 34 & 23 & 3 & 100 & 385 \\
\hline $\begin{array}{l}\text { Immigrant, } \\
10+\text { years }\end{array}$ & 45 & 5 & 31 & 16 & 4 & 100 & 2,167 \\
\hline \multicolumn{8}{|c|}{ Public Use Microdata Sample (2000) } \\
\hline $\begin{array}{l}\text { Immigrant, } \\
0-4 \text { years }\end{array}$ & 19 & 6 & 49 & 22 & 5 & 100 & $7,964,132$ \\
\hline $\begin{array}{l}\text { Immigrant, } \\
\text { 5-9 years }\end{array}$ & 18 & 6 & 49 & 22 & 5 & 99 & $5,934,279$ \\
\hline $\begin{array}{l}\text { Immigrant, } \\
10+\text { years }\end{array}$ & 28 & 6 & 43 & 20 & 3 & 100 & $20,180,948$ \\
\hline
\end{tabular}


likely to participate in surveys (Government Accountability Office 1998). One study conducted by the Census Bureau's Research Division found that, among Latino immigrants in San Francisco, "the most common response [to Census enumerators] was one of fear" (Romero 1992) (Table 6).

Open Access This article is distributed under the terms of the Creative Commons Attribution Noncommercial License which permits any noncommercial use, distribution, and reproduction in any medium, provided the original author(s) and source are credited.

\section{References}

Alba, R.D., Logan, J.R., Crowder, K.: White ethnic neighborhoods and assimilation: the greater New York region 1980-1990. Soc. Forces 75(3), 883-909 (1997)

Blumenberg, E., Shiki, K.: Transportation assimilation: immigrants, race and ethnicity, and mode choice (Paper \#07-2475). In: Transportation Research Board Annual Meeting, Washington, DC (2007)

Bohon, S., Stamps, K., Atiles, J.: Transportation and Migrant Adjustment in Georgia. Popul. Res. Policy Rev. 27, 273-291 (2008)

Boyd, M.: Family and personal networks in international migration: recent developments and new agendas. Int. Migr. Rev. 23(3), 638-670 (1989)

Brownstone, D., Golob, T.F.: The effectiveness of ridesharing incentives-discrete-choice models of commuting in Southern California. Reg. Sci. Urban Econ. 22(1), 5-24 (1992)

Casas, J., Arce, C., Frye, C.: Latino immigration and its impact on future travel behavior. In: National Household Travel Survey Conference. Understanding Our Nation's Travel. Transportation Research Board, Washington, DC (2004)

Charles, K.K., Kline, P.: Relational costs and the production of social capital: evidence from carpooling. Econ. J. 116(511), 581-604 (2006)

Chatman, D.G., Klein, N.: Immigrants and travel demand in the United States: implications for transportation policy and future research. Public Works Manage. Policy 13(4), 312-327 (2009)

Choldin, H.M.: Kinship networks in the migration process. Int. Migr. Rev. 7(2), 163-175 (1973)

Cline, M.E., Sparks, C., Eschback, K.: Understanding carpool use among Hispanics in Texas (Paper \#091585). In: Transportation Research Board Annual Meeting, Washington, DC (2009)

Ellis, M., Wright, R., Parks, V.: Work together, live apart? Geographies of racial and ethnic segregation at home and at work. Ann. Assoc. Am. Geogr. 94(3), 620-637 (2004)

Esser, H.: Does the "new" immigration require a "new" theory of intergenerational integration? Int. Migr. Rev. 38(3), 1126-1159 (2004)

Ferguson, E.: The rise and fall of the American carpool: 1970-1990. Transportation 24(4), 349-376 (1997)

Government Accountability Office: Immigration Statistics: Information Gaps, Quality Issues Limit Utility of Federal Data to Policymakers. GAO/GCD-98-164, Washington, DC (1998)

Heisz, A., Schellenberg, G.: Public transit use among immigrants. Can. J. Urban Res. 13(1), 170-191 (2004)

Hwang, K., Giuliano, G.: The determinants of ridesharing. Literature review, Working Paper, UCTC No. 38. University of California Transportation Center (1990)

Levin, I.P.: Measuring tradeoffs in carpool driving arrangement preferences. Transportation 11(1), 71-85 (1982)

Li, W.: Anatomy of a new ethnic settlement: the Chinese ethnoburb in Los Angeles. Urban Stud. 35(3), 479-501 (1998)

Logan, J., Zhang, W., Alba, R.D.: Immigrant enclaves and ethnic communities in New York and Los Angeles. Am. Sociol. Rev. 67, 299-322 (2002)

Lovejoy, K., Handy, S.: A case for measuring individuals' access to private-vehicle travel as a matter of degrees: lessons from focus groups with Mexican immigrants in California. Transportation 35, 601-612 (2008)

Mahler, S.: American Dreaming: Immigrant Life on the Margins. Princeton University Press, Princeton, NJ (1995)

Massey, D.: Ethnic residential segregation: a theoretical synthesis and empirical review. Sociol. Soc. Res. 69, 315-350 (1985)

McFadden, D.: Measurement of urban travel demand. J. Public Econ. 3(4), 303-328 (1974)

McGuckin, N., Srinivasan, N.: National Summary, Journey to Work Trends in the United States and its Major Metropolitan Areas 1960-2000. FHWA-EP-03-058 (2003) 
McGuckin, N., Keyes, M., Banks, D.: Are households with interrupted phone service like those with no telephone service? Comparison using Public-Use Microdata Set and Nationwide Personal Transportation Survey. Transp. Res. Rec. 1768, 99-105 (2001)

Myers, D.: Changes over time in transportation mode for journey to work: effects of aging and immigration. In: Decennial Census Data for Transportation Planning: Case Studies and Strategies for 2000, vol. 2: Case Studies. Transportation Research Board, Washington DC (1996)

Novaco, R.W., Collier, C.: Commuting Stress, Ridesharing, and Gender: Analyses from the 1993 State of the Commute Study in Southern California. Working Paper, UCTC No. 208. University of California Transportation Center, Berkeley (1994)

Pisarski, A.: Commuting in America III. NCHRP Report 50. TCRP Report 110. Transportation Research Board, Washington, DC (2006)

Portes, A., Bach, R.L.: Latin Journey. Cuban and Mexican Immigrants in the United States. University of California Press, Berkeley (1985)

Purvis, C.: Commuting patterns of immigrants. In: Federal Highway Administration, Bureau of Transportation Statistics, Federal Transit Administration. CTPP 2000 Status Report. U.S. Department of Transportation, Washington, DC (2003)

Richardson, A.J., Young, W.: Spatial relationship between carpool members' trip ends. Transp. Res. Rec. 823, 1-7 (1981)

Romero, M.: Counting the Uncountable: Immigrant and Migrant, Documented and Undocumented Farm Workers in California. U.S. Census Bureau, Statistical Research Division Report EV92-18 (1992)

Rosenbloom, S.: Transit Markets of the Future. The Challenge of Change. Transit Cooperative Research Program. Report 28. National Academy Press, Washington, DC (1998)

Tal, G., Handy, S.: The Travel Behavior of Immigrants and Race/Ethnicity Groups: An Analysis of the 2001 National Household Travel Survey. Report No. UCD-ITS-RR-05-24. Institute of Transportation Studies, University of California Davis (2005)

Teal, R.: Carpooling: who, how and why. Transp. Res. A 21A(3), 203-214 (1987)

U.S. Census Bureau: Census 2000 Summary File (SF 3), Sample Data (2000)

U.S. Census Bureau: The Foreign Born Population in the United States: 2003. Washington, DC (2004)

U.S. Department of Homeland Security: Yearbook of Immigration Statistics: (2006). Office of Immigration Statistics, Washington, DC (2007a)

U.S. Department of Homeland Security: Estimates of the Unauthorized Immigrant Population Residing in the United States: January 2006. Office of Immigration Statistics, Washington, DC (2007b)

U.S. Department of Transportation: 2001 National Household Travel Survey. Bureau of Transportation Statistics, Washington, DC (2004). (raw data)

Van Lange, P.A.M., Ban Vugt, M., Meertens, R.M., Ruiter, R.A.C.: A social dilemma analysis of commuting preferences: the roles of social value orientation and trust. J. Appl. Soc. Psychol. 28(9), 796-820 (1998)

\section{Author Biographies}

Evelyn Blumenberg is Associate Professor of Urban Planning at the University of California, Los Angeles. Her research examines the effects of urban structure-the spatial location of residents, employment, and services-on economic outcomes for low-wage workers, and on the role of planning and policy in shaping the spatial structure cities.

Michael Smart is a doctoral student in the Urban Planning Department at the University of California, Los Angeles. His research interests are demographic change and travel, transportation equity, and transportation and economic development. 